\title{
Officer Perceptions of the Impact of Mobile Broadband Technology on Police Operations
}

\author{
Jeremy G. Carter, Ph.D. ${ }^{1}$ \\ Eric Grommon, Ph.D. \\ Indiana University - Purdue University Indianapolis, USA
}

\section{Citation:}

Carter, J. G. \& Grommon, E. (2015). Officer perceptions of the impact of mobile broadband technology on police operations. Policing \& Society. DOI:10.1080/10439463.2015.1112388.

\begin{abstract}
Research examining police department use of technology is underdeveloped relative to other areas of policing inquiry. This gap in the literature is troubling as policing models are becoming more data-driven and thus, relying more heavily on information technologies. Arguably, the most commonly utilized technology in policing practice, and examined in policing research, has been mobile computers. However, there has been little insight into the technological advancement in data communications that directly influence the functionality of mobile computers. The present research seeks to inform this shortcoming by examining a police department that implemented a dedicated wireless mobile broadband capability in comparison to commercial cellular data access. A mixed methods approach is employed within a medium-sized department in the northeast region of the United States. Survey data was gathered from 76 uniformed police personnel. Semistructured interviews were conducted with key personnel to further contextualize survey results. Survey results suggest tentative support for improved information flow, quality, and accessibility after the implementation of wireless broadband. Perceptions of mobile broadband impacts on time savings and the execution of job tasks appear positive. Considerations for future research and study limitations are discussed.
\end{abstract}

Keywords: Mobile broadband, Mobile computing, Technology adoption, Police operations

Acknowledgements: The authors would like to thank the National Institute of Justice for their financial support of this research. The authors would also like to thank Dr. Nancy Merritt, Joseph Heaps, Phil Harris, Fred Frantz, and Scott Wilder for their insights in shaping this research.

Funding: The authors disclosed receipt of the following financial support for the research, authorship, and/or publication of this article: National Institute of Justice, U.S. Department of Justice (award number: 2010-IJ-CX-K023). The opinions, findings, conclusions, and recommendations expressed in this report are those of the authors and do not necessarily reflect those of the U.S. Department of Justice, Office of Justice Programs, National Institute of Justice. The authors have no vested interests in commercial communication technology products, processes, or services.

\footnotetext{
${ }^{1}$ Author correspondence: Jeremy G. Carter, Ph.D., carterjg@iupui.edu
} 


\section{Officer Perceptions of the Impact of Mobile Broadband Technology on Police Operations}

\section{Introduction}

Research at the intersection of technology and policing has unfortunately not kept pace with technological innovations within police agencies. One area in need of attention is communications infrastructure as police operations are inhibited by poor large data bandwidth coverage and capacity (Hollywood et al. 2015; Silberglitt et al. 2015). As part of a broader mixedmethods federally-funded project focused on one agency's transition from cellular-based communications to a dedicated wireless mobile broadband network ${ }^{1}$, the purpose of this study is to capture end-user perceptions of the deployment and explore the efficacy of broadband technology on police operations. Wireless mobile broadband provides a platform by which the various forms of communications and information technology used in police settings can be unified into a single system. In turn, wireless mobile broadband has the potential to improve police service quality, performance, or outcomes. The present study examines the unexplored potential of wireless mobile broadband. One primary research question guides this effort: did the transition to wireless mobile broadband have any effect on police operations related to the completion of job and administrative tasks and information sharing? This research provides unique insights to both further the understanding of police technology in general and mobile broadband capabilities more specifically.

\section{Technology and Policing}

Information technologies play a central role in facilitating new approaches to policing across the U.S., Europe, New Zealand, Canada and Australia. Advances in computing have improved the ways law enforcement collects, uses, and disseminates data and information (Nunn 
2001). These advances have helped translate conceptual policing philosophies such as problemoriented policing and intelligence-led policing into practice (Braga and Weisburd 2006). This is especially true when considering that contemporary policing efforts in the US, UK, and Australia embrace an inter-agency model of cooperation for reducing crime, disorder, and threats of terrorism (Carter and Phillips 2013; Ratcliffe 2008). The promise of technology coupled with anecdotal evidence on improvements in effectiveness and efficiency of police organizations has resulted in increased technology prevalence in police work (Ericson and Haggerty 1997; Manning 1992a; 1992b; 2008).

The movement towards mobile information technology in the U.S. has largely shaped contemporary police practice (Hollywood et al., 2015; Koper et al., 2015; Manning, 2003). This momentum is likely to continue with the on-going construction of FirstNet, a nationwide wireless broadband network dedicated to public safety as part of The Middle Class Tax Relief and Job Creation Act of 2012 (National Telecommunications and Information Administration 2012). Within the UK, there is currently an e-policing initiative to mobilize information in order to make it more readily available to officers through mobile computing (Povey 2001). This initiative currently enables officers to access information on the police national computer via handheld personal devices, in-vehicle mobile data terminals, or other mobile tablets or laptops. Australia has a similar system to facilitate cross-state and territory information sharing to prevent crime and guide decision making. One of the noted limitations of this information sharing system is a continued reliance on cellular data networks for data access (Commonwealth of Australia 2013). Lastly, the New Zealand Police (NZP) has deployed more than ten thousand mobile devices equipped with data capabilities as part of the Policing Excellence Initiative. Also reliant on cellular 
data capabilities, this program seeks to establish NZP as a highly mobile and data-driven organization that adopts a business model of police efficiency (New Zealand Police 2013).

Police organizations expect two outcome benefits attributed to mobile technologies: betterinformed officers and improved coordination of limited resources at both the micro (officer) and macro (agency) levels. These benefits manifest themselves in the form of improved public service, acute in-field decision-making, real-time data sharing among patrol officers in the field, and improved data access for on-going investigations. Furthermore, real-time data inputs and outputs translate to managerial components of policing where patrol supervisors or police commissions are able to query information and allocate resources in the field. It is imperative to remain conscious of the fact that the effectiveness of mobile computing within the context of policing is not contingent on the quantity of encounters, but the quality of interaction between an officer and the technology he/she is utilizing. Successful use of technology in policing is not reflective of a linear relationship between increased use and increased utility.

This importance is reinforced by Manning (1992a) who asserts that the mere availability and accessibility of information does not equate to effective information use. Rather, successful outcomes of mobile computing technology rely on availability, accessibility, and time. Availability and accessibility are typically considered as a dichotomy; either information is available and accessible or it is not. A more refined interpretation is that availability and accessibility should be viewed as contingent; information is available if and when the technology works correctly. More pertinent to the present research is an emphasis on time. An officer must be able to retrieve necessary information at a point in time when it is most relevant and within an interval that is optimal. 


\section{Mixed Evidenced of Information Technology and Police Operations}

Investments in information technology by police agencies are often justified under the assumption that more information is better than less information (Manning 1996). Research assessing potential returns on information technology investments has focused on an array of policing functions. Evidence has been mixed with productivity findings that range from improved (Colvin and Goh 2005), to less efficient (Manning 2001), and to no observed impacts on productivity and efficiency (Nunn and Quinet 2002). In one of the more comprehensive studies of the interaction between police performance and information technology, Chan (2001) employed a representative non-random survey of 506 officers, completed 23 interviews with key personnel, conducted 11 focus groups with 106 participants of varying personnel, and documented over 30 hours of ride along observations to examine the impact on police operations. The results indicated that police officers spent, on average, three hours and thirty seven minutes per eight hour shift using information technology to complete administrative tasks. Respondents' assessments of their own productivity suggested improvements; the available information technology system allowed respondents to work more effectively, made work easier, and helped them access information needed to do work properly.

Scholars have also found information technologies to be disappointing for police practice; noting that the initial expectations of what the information technology can provide or facilitate does not meet the realities of police work (Manning 1992a, 2003). Others have found unintended consequences related to the integration of information technology systems in policing. Ericson and Haggerty (1997) found an increase, rather than decrease, in paperwork processing and heightened perceptions of police work being more office-oriented rather than less in their in depth examination of Canadian police officer activity. Furthermore, the use of technology may increase 
productivity without resulting in any gain in efficiency as officers have been found to spend more time reporting when using an information technology system compared to hand-written field reports (Henman and Marston 2008; Ioimo and Aronson 2004). Recent research has demonstrated the potential for lost time as technology learning curves reduce the amount of time available to complete crime enforcement functions (Koper et al. 2015).

\section{Mobile Computing}

Prior to mobile computing, officers obtained information primarily through radio dispatch and on-paper procedures, whereas modern systems integrate communication tasks into a single, officer-controlled system known as a mobile data terminal (MDT) (Brewer 2008). As of 2007, $90 \%$ of officers in United States local police departments serving 25,000 or more residents used some form of in-field computer system (Reaves 2010). This number has since likely risen given improvements in functionality and decreases in market price point for in-vehicle technology. These modern MDT systems have provided officers a mechanism to gain faster and more secure access to comprehensive information (Hampton and Langham 2005). Examples of such information include photographs, videos, comprehensive criminal history reports, be-on-the-lookout (BOLO) bulletins, crime maps, and intelligence products. Research on police use of MDTs indicates officers spend anywhere from 13 percent (McKinnon et al. 2012) to 45 percent ( $\underline{\text { Chan }}$ 2001) of an eight hour shift using mobile computers.

A recent study of five agencies in the United Kingdom examined police acceptance of mobile information technologies and concluded that officer acceptance of mobile technologies was contingent upon the reliability and functionality of the device (Lindsay et al. 2014). Using a random survey of 100 members of a medium-sized police agency in Arizona, Ioimo and Aronson 
(2004) conducted a similar, but more comprehensive, study of perceptions pertaining to police mobile computing. This study gleaned measures from previous individual-level technology studies and asked officers if MDTs allow them to complete their tasks with more speed, quality, ease and control (Davis 1989; Moore and Benbasat 1992), as well as less error (Leonard-Barton and Deschamps 1988). Respondents were also asked how MDTs affected the effectiveness, performance, and productivity of their tasks (Davis 1989; Moore and Benbasat 1992). Ioimo and Aronson (2004) concluded that inquiries to local, state, and national criminal information databases increased with the implementation of mobile computing and that field officers recognized the potential benefits mobile computing afforded them. However, field officers also reported that the amount of time required for completing reports increased with the implementation of field mobile computing. This is an important unintended consequence of mobile computing and appears to be a product of increased reporting fields.

Agrawal et al. (2003) utilized survey data of 153 patrol officers who employed mobile computing to study its impacts on critical factors that affect the work environment of officers. Perhaps the most notable finding from this study was that time saved by officers as a result of utilizing MDTs was equivalent to the work performed by approximately 10 percent of the officer work force. Moreover, Agrawal et al. (2003) concluded that officers felt safer in neighborhoods perceived as dangerous because they were able to quickly query information on dangerous elements in the area whereas before officers had to rely on their personal knowledge.

\section{Wireless Broadband Technology to Enhance Mobile Computing}

Police departments currently rely on the use of commercial, cellular-based, wireless communications technology within police patrol vehicles (Argawal et al. 2003; Hampton and 
Langham 2005). Commercial cellular providers partner with law enforcement agencies to provide service at a price deemed reasonable for those agencies. Commercial services often present agencies with a convenient and affordable upgrade from lower bandwidth resources. For example, commercial services can facilitate performance improvement over narrowband data channel legacy technologies and provide improved user access to information and the sharing of data files. However, the utility of commercial cellular services for public safety are often hampered by a number of mitigating factors: limited cellular network coverage, available cellular network capacity, data roaming limitations, unpredictable quality of service through the network, lack of priority access to connect when the commercial network is congested, and network robustness. Each has become a concern for most first response applications (Doumi et al. 2013).

Location is a critical factor influencing commercial cellular network coverage, network capacity, and network robustness. Commercial cellular connection speeds and connection availability are also both contingent upon the proximity of end users in relation to cellular towers. Tower deployment determines network coverage, and network design choices often result in areas with no coverage and lower net capacity near the edge of a given cell site coverage area. Devices operating in distant proximity locations often cannot reliably communicate with the network to support large bandwidth data (Sharma and Jain 2010). Within areas dominated by tall buildings, mountains, or other large physical obstacles that interfere with radio communication waves and reduce signal strength (Chandra et al. 2011; Lia et al. 2008).

Wireless mobile broadband technology presents an alternative to cellular data and networks. Mobile broadband technology can be designed to fill coverage gaps and provide stronger, more reliable signal strengths (Amaldi et al. 2008). These networks can often be designed to provide large bandwidth capabilities across diverse terrains (Marina et al. 2010). 
Perhaps most importantly, wireless mobile broadband can meet the contemporary demands of police personnel and unlock the hidden potential of information technology systems and MDTs. Webb (2004, p. 28) noted the data speeds offered by wireless broadband allow officers to complete all necessary tasks remotely from the patrol car:

"To replicate the office environment in the field requires broadband rates in excess of one megabyte per second. This speed allows an officer to access information quickly and do all paperwork in the patrol car. Broadband also enables voice and real-time video to be streamed to and from the patrol car. Officers can pull up feeds from fixed cameras and see real-time video while supervisors or dispatchers can see and hear what is happening in the vicinity of other units."

The potential benefits of mobile computing via broadband access are not strictly limited to officers using it in patrol cars. Ioimo and Aronson (2004) claim in their six year-long study that non-patrol sections of the police department, such as records, investigative, and administrative personnel, also experience increases in efficiency with MDTs. It is anticipated that these efficiencies would continue to improve with a reliance on a wireless broadband network. In a case study on the transition to cellular wireless communication by the Rockford (Illinois) Police Department (RPD), the sharing of information over a larger bandwidth was achieved (Sprint, 2007). In turn, RPD experienced improvements in the accuracy of their internal record management system and increased time savings on report writing and associated job tasks. Similar or amplified gains are to be expected with the movement from cellular wireless communication systems to wireless mobile broadband.

Unfortunately, few empirical studies have attempted to examine the effects of a change to a wireless mobile broadband infrastructure and determine if this type of network can improve 
police service quality, performance, or outcomes. In one of the rare studies of mobile broadband in policing, Carter and Grommon (2014) concluded that the implementation of a mobile broadband network serving a municipal police department significantly reduced the time to clear calls for service. After action reports have detailed how critical wireless mobile broadband infrastructure is for supporting agency operations relative to cellular-based wireless technology. For instance, a report examining the 2007 bridge collapse in Minneapolis, Minnesota concluded that the available broadband network was “...fast and robust enough to handle large, data-intensive geographical information services (GIS) maps...there is no way [law enforcement and fire teams] could have downloaded or worked on all those heavy GIS maps, big bandwidth users, on a cellular network" (ENCOM Wireless 2010, p. 35).

\section{Existing Literature and the Present Study}

Available evidence related to information technology in policing suggests the adoption of new technologies is beneficial, but burdensome. This line of research, and others external to policing, suggests technology procurement is inevitable and future examinations are needed to inform procurement decisions. The present study extends existing literature on communications and information technologies in policing to capture perceptions of police service quality and performance associated with the deployment of a new technology, but also provides two distinctly new contributions. First, wireless mobile broadband is an infrastructure-based technology operating in the "background" to meet communications and information technology needs and does not involve direct human-technology interaction.

For example, officers directly interact with mobile computer hardware as they complete reports and run information queries. In contrast, wireless mobile broadband does not necessarily 
change the officer's interactions with the mobile computer; it simply improves the process through faster and more reliable data connections. Second, virtually all technology studies to date have examined a new technology in comparison to the absence of the new technology (i.e., reporting with or without a computer). The present study compares officer perceptions of an improved technology (i.e., wireless mobile broadband) to a less reliable and efficient technology (i.e., cellular air-cards), the latter of which are more commonly utilized in contemporary policing and provide a relatable perspective for many agencies worldwide. Related to this second point, recent research examining a range of technologies in policing suggests that variation in the quality and features of information technology systems is a significant factor that requires further exploration (Koper et al. 2015).

\section{Methods}

Data

This research was conducted within a single medium-sized police agency in the northeast region of the United States with a population of 58,732 (U.S. Census Bureau 2010). The police department in this study had 140 sworn officers, two information technology officers, one analyst, 16 full-time civilian dispatch, and 24 full-time civilian support staff. More than half $(60 \%)$ of sworn officers had advanced education beyond a bachelor's degree. The department recently replaced their legacy wireless data communication system of commercial cellular air-cards with a wireless 4.9-ghz mobile broadband communication system. The impetus for the transition was largely due to poor signal strength across patrol sectors resulting from topographic and infrastructure barriers. In theory, the dedicated mobile broadband system will provide uninterrupted coverage to all patrol sectors and thus improved data speeds and reliability. 
The decision to conduct the study at this agency was rather straightforward: the agency possessed an operational mobile broadband system with ubiquitous coverage across the entire jurisdiction. Moreover, the chosen agency had previous experience with cellular-based data communications to which mobile broadband could be compared. This infrastructure is currently exceedingly rare among municipal police agencies. However, substantial gains in adoption of mobile broadband are anticipated with the eventual rollout and completion of the aforementioned FirstNet and similar efforts in the United Kingdom and Australia. Thus, this research offers preliminary evidence on the potential of wireless mobile broadband for policing, which has direct policy implications for government officials, police administrators, and command staff and will be an arena for important scholarly research.

The present study employs a mixed-methods approach that uses a web-based self-report survey administered to all sworn police department personnel as well as semi-structured interviews with key personnel who possessed intimate knowledge of implemented technology. The decision to survey only sworn officers was driven by the fact that these individuals most accurately represented end-users of mobile broadband technology as they continuously used this technology within their patrol vehicles in the field. Analyst and investigatory personnel are also likely to benefit from the implementation of mobile broadband. However, preliminary discussions with department administrators and personnel indicated that their interaction with the technology was limited.

The web-based survey was distributed to all uniformed personnel through their departmental email addresses. Announcements and reminders to complete the survey were made during in-service training sessions across a four month period. Access to the survey was available at the station at desktop computer terminals as well as personal home computers during off hours. 
The final sample consisted of 76 respondents and represents $62 \%$ of the department personnel who were active for duty at the time of the survey. This rate of response is consistent for exploratory web-based surveys in social science (Brick and Williams 2013; Sheehan 2001). In an effort to determine the presence of a non-response bias, the authors explored the agency's information reported in the 2007 Law Enforcement Management and Administrative Survey (LEMAS) across staff, gender, and race/ethnicity demographics. Though not a pristine comparison, the sample that responded to the survey appear to be representative of the greater population of uniformed personnel. While non-response bias cannot be completely ruled out, the likelihood this form of bias drove the overall results is low. Table 1 displays survey respondent demographics. On average, respondents had been employed by the department for almost 18 years, possessed a graduate degree, and were white males over the age of 38. Most of the respondents were assigned to patrol.

[ Table 1. Respondent Demographics ( $\mathbf{N}=\mathbf{7 6})$ approximately here ]

The survey instrument was designed to capture a variety of dimensions associated with wireless broadband and police operations. Many of the dimensions and their underlying items were adapted from previous research and found to possess adequate levels of measurement reliability and validity (Chan 2001; Chan et al. 2001; Ioimo and Aronson 2004). Items consisted of statements intended to prompt perceptual and/or attitudinal responses.

One of the challenges with trying to measure new technology impact among a sample of end-user respondents who may not possess baseline technical knowledge about technology is the need to develop items that resonate with respondents. One form of hardware familiar to all 
personnel in the department were mobile computer terminals. Mobile computer terminals were used prior to and after wireless broadband implementation. However, implementation enabled the expanded use of mobile computer terminals and their inherent software programs and applications. Prior to wireless broadband, officers were unable to reliably submit reports while remaining in their patrol zone due to poor cellular data coverage, officers could not access the full suite of software applications available on desktops in the station, officers would experience significant delays in information requests during peak cellular hours, officers were unable to access large data files such as pictures, videos, building specifications, and other forms of detailed information on the department intranet, and officers could not use programs and applications simultaneously. These problems were remedied following the implementation of wireless broadband.

Department mobile computer terminals and software programs and applications served as a useful frame of reference for respondents. First, respondents possessed firsthand user knowledge about the terminals and the programs and applications. Second, the terminals, programs, and applications were in operation before and after the transition to wireless mobile broadband. Prior to deploying the wireless mobile broadband network, terminals, programs, and applications were operating under a commercial, cellular-based, communications infrastructure. Third, respondents were aware of the timeline surrounding the implementation of the wireless mobile broadband network. The agency's Director of Technology provided in-person updates during various inservice trainings or roll calls and electronic updates through the intranet about the build out process and when the network would become operational. Instead of communicating technical detail to personnel, updates provided by the Director of Technology highlighted how the transition will improve experiences with mobile computer terminals and software programs and applications. 
The survey instrument was pre-tested, reviewed, and vetted by the United States' National Institute of Justice's Communication Technology Working Group. ${ }^{2}$ Closed-ended items included Likert style response sets in matrix format with no neutral category provided. Response sets ranged from "strongly disagree" (one) to "strongly agree" (four). Higher scores therefore indicate higher levels of agreement with an item. In addition to the survey, one site visit was conducted for the sole purpose of administering a semi-structured interview protocol with key personnel. Three criteria were used to generate an interview sample. First, the sample had to possess expertise about, or knowledge of, the wireless broadband network and its functional capabilities. Second, members of the sample must have been employed by the department prior to the wireless broadband network implementation. Third, representatives from a full range of department roles were selected in an effort to increase variability in responses.

The research team worked with the department's Director of Technology to identify members of the interview sample. A total of five uniformed personnel were interviewed in depth. Respondents included the Chief of Police, Director of Technology, one Sergeant of the Patrol Division, one Lieutenant of the Training Division, and one Analyst. Interview questions, and probing items, were designed to elicit discussions of whether mobile broadband was perceived to have any effect on job tasks associated with specific roles. The limited literature specific to mobile computing, technology implementation, and information technology within policing was leveraged to guide the construction of the semi-structured interview instrument.

\section{Analytic Strategy}

Descriptive findings are reported and discussed. A total of 34 indicators were used to measure various aspects of perceived outcomes related to mobile broadband data communications. 
Given the sparse research to date related to large bandwidth data communications in policing, responses across each of the four categories are presented in figure format. Valid percent is presented along the $\mathrm{x}$-axis containing available response categories. Means and standard deviations are also reported in these figures. Reliability coefficients (alpha) are provided to demonstrate internal consistency across the items presented within groups.

Semi-structured interview data was constructed from interview notes taken by three members of the research team, all of whom were present and took notes during each interview. These notes were consolidated into partial transcription files for each interviewee. The primary analytic strategy consisted of open coding whereby interview data was classified into thematic categories (Strauss and Corbin, 1990). Two members of the research team then reviewed the coding schemes independently, discussed categories, and achieved consensus on the primary and secondary themes generated from the interview data. These results were then integrated into the discussion of the survey results as quantitative findings are best contextualized through discussions with persons who had direct interaction with the area of study to better inform policing research and policy directions (Greene 2014).

\section{Findings}

The findings are presented in two sections. First, results on the perceived impact of the transition to wireless mobile broadband on job tasks and performance are provided. Second, perceptions of the impact the transition had on information access and quality are detailed. 


\section{Job Impact}

The extent to which wireless mobile broadband impacts police operations is explored through dimensions of job effectiveness and time savings. Figure 1 illustrates respondents' perceptions of impact on their job resulting from the implementation of mobile broadband. A general trend appears that most respondents agree or strongly agree that mobile broadband, in comparison to cellular communications, has a positive impact on their job. On average, respondents perceived mobile broadband as improving work productivity, self-initiating activities, and generally do a better job. Moreover, the average respondent indicates that mobile broadband better facilitates job activity related to license plate checks, arrests, and serving the public. The proportion of respondents indicating negative responses was mixed evenly across personnel types. Though it cannot be validated with the available data, interviews with agency personnel indicate the improvement in data quality and timeliness of information has led to a perceived increase in arrests. Through discussions with agency personnel, this perception is likely driven by more robust information available to officers on the street. For example, following the implementation of mobile broadband, officers were able to receive "be on the lookout" (BOLO) bulletins that included offender pictures and detailed information. This capability allows officers to more specifically identify persons of interest.

[ Figure 1. Mobile Broadband Impact on Job Performance $(\boldsymbol{n}=76)$ approximately here ]

Figure 2 reports items pertaining specifically to mobile broadband compared to cellular data communications and the problem of poor signal strength via cellular data services in patrol sectors. Respondents, on average, preferred mobile broadband over cellular air-cards. The 
availability of strong data communications was perceived to be important as respondents indicated that varying signal strength across patrol sectors was a problem and when working in a patrol sector with a weak cellular data signal would change their method for completing job tasks. This latter point is rather insightful as it speaks to the fact that officers, on average, will do tasks differently in areas with poor cellular coverage. This likely reflects officers' reporting method wherein they will likely wait to submit reports at the end of their shift at the department as opposed to remotely from their vehicle as soon as the report is completed.

Perhaps most noteworthy in Figure 2 is that wireless mobile broadband is a perceived improvement upon the past reliance on commercial cellular air-cards. On average, respondents indicated that mobile broadband allowed for information to be accessed easier, was faster, and the amount of information that could be accessed was improved as compared to cellular data service. These findings lend tentative support to the anecdote that operational police behavior is altered to adapt to available technology systems. Whether an officer is engaged in report writing and submission, operating a license plate reader, collecting and sharing real-time data, or querying information, they are reliant on data transfer. These findings illuminate how a reliable and largebandwidth data connection can influence such behaviors.

[ Figure 2. Mobile Broadband vs. Cellular Data Communications $(\boldsymbol{n}=76)$ approximately here ]

The impact on time has been the focal point in policing technology debates as arguments have been made that mobile computing has both decreased and increased time officers spend completing job tasks (Chan 2001; Chan et al. 2001; Ioimo and Aronson 2004). Figure 3 illustrates respondents' perceptions of time savings resulting from the implementation of mobile broadband. 
Overall it appears respondents perceive mobile broadband to afford time savings compared to cellular data. However, these findings are rather mixed and less definitive. On average, respondents agree that mobile broadband has resulted in fewer trips to the station. This was a welcomed finding as interviews with department personnel indicated the desire to create a mobile environment where officers remained in their patrol sectors while reporting in real-time was a significant motivation for mobile broadband adoption. Moreover, respondents indicated that, on average, they believed mobile broadband reduced the overall time pressures of their job. On average, respondents believe that mobile broadband reduced time spent reporting, roll call and perceived time spent on administrative tasks at the station. Though this appears promising, the overarching trend depicted by respondents' perceptions of mobile broadband is barely favorable. Moreover, the data does not allow for refined analyses that could better parse out time savings.

However, further analysis showed that only 58 percent of patrol officers perceived mobile broadband to reduce the overall time pressures of their job. This is in contrast to the 72 percent of other personnel within the department who had similar beliefs. Thus, patrol officers reported less perceived time savings than other personnel. Such findings are consistent with previous research on police mobile computing in which patrol officers felt other personnel within the department would benefit from their increased efforts in mobile computing (Ioimo and Aronson 2004). An example was illustrated during an interview with a patrol sergeant who indicated that patrol officers may feel detectives and analysts are able to more efficiently query information they need, which in turn makes their jobs easier. This ability to query specific information quickly would not be possible without officers imputing the information from the field via mobile computing.

[Figure 3. Respondent Perceptions of Time Impact from Mobile Broadband ( $n=76)$ approximately here ] 


\section{Information Impact}

Improvement across multiple information-related metrics is the catalyst behind mobile broadband implementation. The extent to which job effectiveness and time savings are influenced by mobile broadband is contingent upon the access to, and quality of, information. Improvement in information technology can be assessed through the perceptions of improved flow and quality of information following the implementation of mobile broadband. Flow of information is mitigated by the quality of information being communicated. If the information being collected, accessed, and shared is of poor quality, it does not matter how accessible or fast the information is - it will not be beneficial to the operations of a police department. Figure 4 displays respondents' perceptions of these anticipated improvements. Three primary trends are reflected in the responses. First, there is belief that information is more easily manageable. On average, respondents indicated information was easy to access, easy to share, and moved more quickly. This is to be expected as data and reports collected in the field are now uploaded automatically into the department's records management system at the time the report is completed in the field. Prior to mobile broadband, "data dumps" would occur at the end of patrol shifts where officers would bring their mobile computers into the station and upload information from their entire shift at once.

Second, the quality of information has improved since the information is now real-time. Department personnel can access information as soon as it is input into the system - there is no lag time where personnel across the organization are waiting for information. Moreover, department personnel employed prior to the implementation of mobile broadband indicated that information they had access to was higher quality and faster to access than before implementation. Third, mobile broadband improves how patrol officers perceive an upcoming encounter. 
Respondents indicated, on average, a belief that mobile broadband allowed them to be more confident and safe when approaching an encounter while also improving the judgment officers use during an encounter. Improved quality of information has been demonstrated to improve officer discretionary decision making (Guyot 1991; Manning 1992). The notion of possessing improved information also positions an officer to be more prepared to make a safe encounter with a citizen.

Insights from the interviews with key personnel lend further support for the quality of information sharing. Related to accessing information immediately preceding an encounter, interviews indicated that detailed reports that included high-resolution photos of persons were critically helpful. Each person interviewed expressed a noticeable improvement in field reporting by patrol officers. When further probed about this perceived improvement, interviewees identified common characteristics of reporting they personally observed to be of higher quality following the adoption of mobile broadband. These characteristics included accuracy of information, availability of information on a real-time basis (specifically emphasized by detectives or investigatory personnel), fewer necessary revisions for reports to be considered complete, and timeliness of submission by patrol officers prior to shift completion. This final point should be elaborated upon as patrol sergeants in the department are responsible for reviewing and approving all field reports from each shift during the day. Prior to the implementation of mobile broadband, patrol sergeants indicated they would have to wait around the station and frequently urge patrol officers to submit their reports for approval. Both sergeants and patrol officers could not go home at the end of their shift until all reports from that day were submitted and approved. It appears mobile broadband substantially facilitated this process.

[Figure 4. Mobile Broadband Impact on Quality of Information ( $\boldsymbol{n}=\mathbf{7 6})$ approximately here ] 
Some of the aforementioned results presented in Figure 4 are consistent with previous research finding a lack of improved time efficiency with mobile computing (Chan 2001, Chan et al. 2001; Ioimo and Aronson 2004). One of the potential pitfalls of enabling more sources of information is "information overload" as well as decreases in job performance and satisfaction. To better understand this potential hindrance, survey items were included to capture adverse effects of mobile broadband. These items were included given the anticipation that mobile broadband would increase the bandwidth to distribute larger amounts of information more quickly. Figure 5 presents items pertaining to perceptions of information overload and negative job attributes resulting from mobile broadband implementation. Generally it appears officers do not perceive to be overburdened with information. On average, respondents note they are responsible for reading more information following the implementation of mobile broadband.

However, respondents on average did not perceive to be receiving too much information or that information overload was specifically a problem. Furthermore, respondents indicate they do not perceive mobile broadband to hinder their job, make their job more difficult, or decrease job satisfaction. It is interesting that respondents report to feel more accountable for their work. Interviews with agency personnel indicate this accountability is likely related to increased reliability of the data network that enables in-field reporting as opposed to uploading reports at the physical department. More specifically, this reporting requirement coincides with a department policy requiring officers to submit reports immediately upon completion in the field given the availability of reliable in-field data communications provided by mobile broadband. Overall, these findings lend tentative support to the notion that officers appreciate the improved quality and timeliness of information resulting from mobile broadband. 
[Figure 5. Adverse Effects of Mobile Broadband ( $\boldsymbol{n}=\mathbf{7 6})$ approximately here ]

\section{Conclusions}

Through the use of a mixed methods approach, the purpose of this study was to examine and describe end-user perceptions of the transition from cellular-based communications to a dedicated wireless mobile broadband network. This study also sought to detail perceptions of the efficacy of this emerging form of technology on police operations. One specific research question informed the study: did the transition to wireless mobile broadband have any effect on police operations related to the completion of job and administrative tasks and information sharing?

Overall, results suggest that the wireless broadband technology may have contributed to a number of perceived benefits for the department. The most direct benefits were associated with increased access to timely information, increased information flow, and increased quality and timeliness of reports. One of the main issues driving the procurement of a broadband wireless network were previous complications with information access, information exchange, and report writing due to unreliable commercial cellular coverage. These results lend partial support to the notion that the broadband network met some anticipated expectations related to information access and exchange, but signal strength and coverage issues in patrol areas continued to be problematic and influence how officers completed job tasks. These findings are consistent with recent research noting that successful information technology adoption in policing is achieved when technology type is matched specifically with police tasking needs (Jackson 2014). 
Implementation and change, however slight, has the potential to create an assortment of problematic unintended consequences. One such potential challenge revealed during interviews was the perceived increase in workload responsibilities associated with report writing by patrol officers. Two dimensions were particularly relevant. First, it was perceived that the transition to wireless broadband increased the amount of data entry fields required to submit reports. Second, and relatedly, these reports were perceived to be subjected to increased supervisory accountability. The web-based survey appeared to provide confirmation of these perceptions. Uniformed personnel perceived they were responsible for reporting more information. At the same time, survey results suggested that personnel perceived they were able to complete reports faster and submit without problems. Moreover, personnel largely agreed that information captured in the reports is more accurate and of higher quality. These perceptions cautiously lend some support to notions of improved report writing, but also suggest that perceptions may be related to other extraneous factors distantly related to network implementation.

Survey findings provide indication that information sharing was likely to be the most beneficial product related to wireless broadband implementation. Information was perceived to be easily accessible, shared, timely, and of better quality, which is consistent with semi-structured interview findings. The benefits inherent to improved information sharing were thought to advance the completion of job tasks and responsibilities; especially those related to reporting. The results of the remaining operational outcomes - job and administrative tasks - were far less definitive. Wireless broadband technology was perceived to enhance the ability of personnel to do their job. Improvements in information flow and quality were central to these perceptions. Patrol personnel expressed perceptions of being more confident and safe during encounters. Report writing was perceived to be completed more efficiently with wireless broadband. 


\section{Limitations}

The subjective interpretation of technology systems, elements, or functions has consistently plagued police technology evaluations (Colvin and Goh 2005). Valid technology

criterion to produce quality data was the focus of a recent report from the Government Accountability Office, specifically noting that "data limitations make it difficult to fully measure the effect of expanding access to, and adoption of, broadband" (U.S. Government Accountability Office 2012, p. 12). Survey items were framed with the use of introductory prompts and repeated cues that directed respondents to consider the end-user hardware and software applications supported by wireless broadband. This approach was necessary since few within the department possessed operational knowledge of network specifications. As a result, stated perceptions may be a function of perspectives indirectly related to wireless broadband technology. Additionally, the potential influence of hindsight, misattribution, or other response biases cannot be completely ruled out from this research or self-reported survey research in general (Czaja and Blair 1996).

Overall the results are favorable of wireless broadband and could perhaps signal a pattern of socially desirable responses on behalf of the respondent. To best safeguard against this shortcoming of survey research, a series of "bogus" items were integrated into the survey to assess respondent response patterns (Meade and Craig 2012). All of these items were in the opposite direction of valid items, which increases confidence in respondent engagement. The two items presented in Figure 5, "Decrease job satisfaction" and "Makes job more difficult," are reverse items and respondents indicate a consistent trend with the overall results. These specific findings reinforce confidence in the results presented. 
Lastly, it should be noted that the agency of study is not reflective of the average agency in the United States, United Kingdom, Australia, Canada or anywhere else in the world. For example, the study agency was comprised of sworn officers who, on average, possessed a graduate degree. The agency is also unique in its ability to navigate through complex private-public partnerships to become one of the first adopters of a dedicated wireless mobile broadband network. The ability to generalize the results of this study to other agencies is limited.

\section{Future Research}

The present study has provided perceptual insights on how the integration of mobile broadband technology may influence police operations for one medium-sized police department. Future replications of this research are needed in an assortment of service settings (e.g., rural, suburban, and urban) involving a wider variety of sworn and non-sworn personnel. Replications must be able to construct a pre-wireless broadband deployment comparison group or timeframe to serve as a baseline to test and generate evidence on the effect of this type of technology.

A delicate balance exists between improving the flow and quality of information across a police department and the added workload burden and responsibility to facilitate these objectives among line-level personnel who are already tasked with an assortment of daily administrative activities. This dynamic has emerged as one of the most consistent findings in the literature on the integration of communications technology in policing (Ericson and Haggerty 1997; Henman and Marston 2008; Ioimo and Aronson 2004; Koper et al. 2015). Police administrators and command staff must be aware of these challenges when seeking to adopt a new form of technology and employ strategies to mitigate personnel concerns. This perceived burden is most likely centered on patrol officers as they represent the common end-user to receive information pushed to them 
for purposes of "for your information" (Lewandowski and Carter 2014). The survey findings reflect officer perceptions of increased reading responsibility. Research should attempt to capture the extent to which this increased burden compounds existing responsibilities. This may be the intersection of true gains in time efficiency and officer productivity. Future research should seek to explore the type of information perceived to be most beneficial for varying personnel types. Relatedly, the type of information that is, and is not, available via different data communication bandwidths may be insightful. This latter point is potentially important for agencies seeking the best data communications for their budget.

Researchers should also consider clearance rates of crime. It appears the speed and quality of information flow improved following broadband adoption. It would seem that as varying police personnel access information that is more real-time and accurate, that an increase (however slight) may be observed among the clearance rates of crimes. A notion exists in the literature that improved information technology will facilitate more frequent community engagement. This assertion rests on the idea that time associated with daily tasks will decrease. The survey results presented here challenge the assumption of increased community engagement.

Inquiries into information technology generally, and broadband data communications more specifically, should take into consideration how time is quantified between tasks and how this time could translate to additional gains in officer activity. It is likely that any gains in time offered by information technology are present in small increments between tasks. For example, if taken in sum this time savings may equate to thirty minutes total across an entire patrol shift. Though this aggregate time savings is theoretically enough time to further engage the community, this time savings never occurs in increments large enough for an officer to engage the community between tasks. A more plausible measure of increased productivity may be the number of unique tasks an 
officer completes in a given shift as a result of broadband data access. As each phase of an officer's task is made more efficient, such as running queries on a driver's license plate, warrant checks, and other records system during a traffic stop, the entire task may be completed more quickly as a result of the successive tasks being expedited.

Information technology units, officers, and/or support personnel activity should be captured where appropriate. Broadband data communications enable remote software updates and management of computer terminals. Not only should this remote access improve the time technicians dedicate to hardware and software maintenance, but it should also maximize hardware usage in the field as mobile terminals should not need to be removed from the patrol vehicle for service.

Lastly, the interrelationship between wireless mobile broadband infrastructure, improved information quality, and officer safety should be further explored. Most of the respondents in this study noted improved accessibility to real-time, up-to-date information and as well as being more prepared upon approach to and more confident while in a situation. While it is not possible to determine causal effects in this study, this preliminary finding begins to address the important intangible dimension of policing. These relationship will perhaps be increasingly relevant as police integrate additional forms of technology, such as body-worn cameras.

It is important to be mindful that technology is inherently neither good nor bad. It is simply a tool to meet goals and objectives. The results of this research suggest that wireless broadband technology may have contributed to perceptions of improved operations. Patrol personnel believed that the change to broadband helped to ease job tasks and enhanced their ability to do their job. Improved information sharing appeared to be the most promising product of the transition to wireless broadband in this study. These findings provide some evidence that investments in 
wireless mobile broadband infrastructure may enhance police service quality, performance, or operations. However, the extent to which the wireless broadband technology subsequently influenced traditional police operations remains far from clear despite some promise from this study. Mechanisms connecting technology benefits with user experiences need to be elaborated to determine how this interaction can shape relevant law enforcement outcomes (Salvendy 2012). Scholars should continue to explore how new technologies facilitate information sharing and advance knowledge on how shared information is consumed and made actionable. Understanding these underlying processes will help inform efforts to examine operational outcomes and generate needed information to justify costs of technology procurements.

\section{Notes}

${ }^{1}$ This research is based on data from the National Institute of Justice award number 2010-IJ-CXK023. The opinions, findings, conclusions, and recommendations expressed in this report are those of the authors and do not necessarily reflect those of the U.S. Department of Justice, Office of Justice Programs, National Institute of Justice. The authors have no vested interests in commercial communication technology products, processes, or services.

${ }^{2}$ For more information visit: http://www.nij.gov/topics/technology/pages/working-groups.aspx

${ }^{3}$ The FCC defines broadband as 4Mbps download speeds and 1Mbps upload speed (Federal Communication Commission, 2012). Until 2010, the commission defined broadband as 200Kbps in both directions, and then adopted the current $4 \mathrm{Mbps} / 1 \mathrm{Mbps}$ definition for the last three broadband progress reports. 


\section{References}

Agrawal, M., Rao, H. R. and Sanders, G. L., 2003. Impact of mobile computing terminals in police work. Journal of Organizational Computing and Electronic Commerce, 13 (2), 73-89.

Amaldi, E., Capone, A., Cesana, M., Filippini, I. and Malucelli, F., 2008. Optimization models and methods for planning wireless mesh networks. Computer Networks, 52 (11), 21592171.

Braga, A. A. and Weisburd, D. L., 2006. Police innovation and the Future of Policing, In Braga, A. A. and Weisburd, D. L. eds., Police Innovation: Contrasting Perspectives, Cambridge University Press: New York, 339-352.

Brewer, B., 2008. Mobile computing lessons learned. Police Fleet Manager, 6 (1), 22-25.

Brick, J. M. and Williams, D. 2013. Explaining rising nonresponse rates in cross-sectional surveys. The ANNALS of the American Academy of Political and Social Science, 645 (1), 36-59.

Carter, J. G. and Grommon, E. L., 2014. Wireless broadband for municipal police: Evaluating clearance times of calls for service. Police Quarterly, 17 (3), 226-249.

Carter, J. G. and Phillips, S. W., 2013. Intelligence-led policing and forces of organizational change in the United States. Policing and Society. Advanced online publication. DOI:10.1080/10439463.2013.865738.

Chan, J. B. L., 2001. The technological game: How information technology is transforming police practice. Criminology and Criminal Justice, 1 (2), 139-159.

Chan, J., Brereton, D., Legosz, M. and Doran, S., 2001. E-policing: The impact of information technology on police practices. Criminal Justice Commission: Brisbane, Queensland Australia.

Chandra, A., Bose, C. and Bose, M. K., 2011. Wireless relays for next generation broadband networks. Potentials, 30 (2), 39-43.

Colvin, C. A. and Goh, A., 2005. Validation of the technology acceptance model for police. Journal of Criminal Justice, 33 (1), 89-95.

Commonwealth of Australia, 2013. CrimTrac Annual Report, Canberra. Available from http://www.crimtrac.gov.au/about_us/documents/CrimTracAnnualReport2012-

13AccessiblePDFforwebsite.pdf (accessed 12 January 2015).

Czaja, R., and Blair, J., 1996. Designing surveys: A guide to decisions and procedures, Pine Forge Press: Thousand Oaks, CA.

Davis, F. D., (1989). Perceived usefulness, perceived ease of use, and user acceptance of information technology. MIS Quarterly, 13 (3), 319-340.

Doumi, T., Dolan, M. F., Tatesh, S., Casati, A., Tsirtsis, G., Anchan, K., and Flore, D., 2013. LTE for public safety networks. Communications Magazine, 51 (2), 106-112.

ENCOM Wireless., 2010. Cellular "data crunch" leaves cities needing dedicated wireless network options. IMSA Journal, 48 (1), 34-39.

Ericson, R. V. and Haggerty, K. D., 1997. Policing the Risk Society. University of Toronto Press: Toronto, Canada.

Federal Communications Commission., 2012 FCC Launches Ninth Inquiry Into Broadband Availability. Available from http://www.fcc.gov/document/fcc-launches-ninth-inquirybroadband-availability (accessed 16 January 2015).

Greene, J. R. 2014. New Directions in policing: Balancing prediction and meaning in police research. Justice Quarterly, 31 (2), 193-228.

Guyot, D., 1991. Policing as Though People Matter. Temple University Press: Philadelphia, PA. 
Hampton, P. and Langham, M., 2005. A contextual study of police car telematics: The future of in-car information systems. Ergonomics, 48 (2), 109-118.

Hollywood, J. S., Woods, D., Silberglitt, R., and Jackson, B. A. (2015). Using Future Internet Technologies to Strengthen Criminal Justice. Priority Criminal Justice Needs Initiative. RAND Corporation: Washington, DC.

Inan, F. A. and Lowther, D. L., 2010. Factors affecting technology integration in K-12 classrooms: A path model. Educational Technology Research and Development, 58 (2), 137-154.

Ioimo, R. E. and Aronson, J. E., 2004. Police field mobile computing: Applying the theory of tasktechnology fit. Police Quarterly, 7 (4), 403-428.

Ironson, G. H., Smith, P. C., Brannick, M. T., Gibson, W. M., and Paul, K. B., 1989. Construction of a Job in General scale: A comparison of global, composite, and specific measures. Journal of Applied Psychology, 74 (2), 193-200.

Jackson, B. A., 2014. How Do We Know What Information Sharing Is Really Worth? Exploring Methodologies to Measure the Value of Information Sharing and Fusion Efforts, RAND Corporation: Santa Monica, Calif.

Koper, C. S., Lum, C., Willis, J. J., Woods, D. J., and Hibdon, J., 2015. Realizing the Potential of Technology in Policing. George Mason University. Police Executive Research Forum. National Institute of Justice: Washington, DC.

Leonard-Barton, D. A. and Deschamps, I., 1988. Managerial influences in the implementation of new technology. Management Science, 34 (10), 1252-1265.

Lewandowski, C. and Carter, J. G., 2014. Intelligence dissemination from a state fusion center in the United States. Security Journal. Advanced online publication. DOI:10.1057/sj.2014.38.

Lia, X. J., Seet, B. C., and Chong, P. H., 2008. Multihop cellular networks: Technology and economics. Computer Networks, 52 (9), 1825-1837.

Lindsay, R., Jackson, T. W., and Cooke, L., 2014. Empirical evaluation of a technology acceptance model for mobile policing. Police Practice and Research, 15 (5), 419-436.

Loehlin, J. C., 1992. Latent Variable Models: An Introduction to Factor, Path, and Structural Analysis (2nd Ed.). Lawrence Erlbaum: Hillsdale, NJ.

Manning, P. K., 2008. The Technology of Policing: Crime Mapping, Information Technology, and the Rationality of Crime Control. New York University Press: New York, NY.

Manning, P. K., 2003. Policing Contingencies. University of Chicago Press: Chicago.

Manning, P. K., 1996. Information technology in the police context: The "sailor" phone. Information Systems Research, 7 (1), 52-62.

Manning, P. K., 1992a. Technological dramas and the police: Statement and counterstatement in organizational analysis. Criminology, 30 (3), 327-346.

Manning, P. K., 1992b. Information technologies and the police. Crime and Justice, 15, 349-398.

Marina, M. K., Dasb, S. R., and Subramanianb, A. P., 2010. A topology control approach for utilizing multiple channels in multi-radio wireless mesh networks. Computer Networks, 54 (2), 241-256.

McKinnon, C. D., Callaghan, J. P., and Dickerson, C. R., 2012. Evaluation of the influence of mobile data terminal location on physical exposures during simulated police patrol activities. Journal of Applied Ergonomics, 43 (5), 859-867.

Meade, A. W., and Craig, S. B., 2012. Identifying careless responses in survey data. Psychological Methods, 17 (3), 437-455. 
Moore, G. C., and Benbasat, I., 1992. An Empirical Examination of a Model of the Factors Affecting Utilization of Information Technology End Users. White Paper, University of British Columbia: Vancouver, British Columbia, Canada.

National Telecommunications and Information Administration., 2012. First Responder Network Authority. U.S. Department of Commerce: Washington, DC. Available from http://www.ntia.doc.gov/files/ntia/publications/firstnet_prospectus_-_final.pdf (accessed 13 March 2015).

New Zealand Police., 2013. Mobility Rollout Concludes Policing Excellence Implementation. National News. Available from http://www.police.govt.nz/news/release/35461 (accessed 14 February 2015).

Nunn, S., 2001. Police technology in cities: Changes and challenges. Technology in Society, 23 (1), 11-27.

Nunn, S., and Quinet, K., 2002. Evaluating the effects of information technology on problem oriented-policing: If it doesn't fit, must we quit? Evaluation Review, 26 (1), 81-108.

Povey, K., 2001. Open All Hours: A Thematic Inspection Report on the Role of Police Visibility and Accessibility in Public Reassurance. Her Majesty's Inspector of Constabulary: London, United Kingdon.

Ratcliffe, J. H., 2008. Intelligence-Led Policing. Willan Publishing: Cullompton, United Kingdom. Reaves, B. A., 2010. Local Police Departments, 2007. US Department of Justice. Bureau of Justice Statistics: Washington, DC.

Salvendy, G., 2012. Handbook of human factors and ergonomics (4th ed.). John Wiley and Sons: Hoboken, NJ.

Sharma, V., and Jain, R. C., 2010. Multi-hop cellular networks: A review. International Journal of Engineering Science and Technology, 2 (11), 6082-6091.

Sheehan, K., 2001. E-mail survey response rates: A review. Journal of Computer-Mediated Communication, 6 (2), 0.

Silberglitt, R., Chow, B. G., Hollywood, J. S., Woods, D., Zaydman, M., \& Jackson, B. A. (2015). Visions of Law Enforcement Technology in the Period 2024-2034. Report of the Law Enforcement Futurnig Workshop. Priority Criminal Justice Needs Initiative. RAND Corporation: Washington, DC.

Sprint., 2007. Mobile Broadband Solutions for the Changing Workplace in Federal, State and Local Government. Sprint Nextel. Available from http://archive.teleworkexchange.com/Sprint-Mobile-Broadband-WP.pdf (accessed 18 January 2015).

Strauss A., and Corbin, J. M., 1990. Basics of qualitative research: Grounded theory procedures and techniques. Sage: Thousand Oaks, CA.

U. S. Census Bureau., 2010. 2010 Census Data. U.S. Department of Commerce: Washington, DC.

U.S. Government Accountability Office., 2012. Broadband Programs Are Ongoing, and Agencies' Efforts Would Benefit from Improved Data Quality. A report to Congressional Committees: Washington, DC.

Webb, M., (2004, June). Wireless Standards to Enable Broadband. The Police Chief, 71 (6), 0.

Zwick, W. R., and Velicer, W. F., 1986. Comparison of five rules for determining the number of components to retain. Psychological Bulletin, 99 (3), 432-442. 


\section{Tables and Figures}

Table 1. Respondent Demographics $(n=76)$

\begin{tabular}{lc}
\hline & Frequency (Percent) \\
\hline Staff Position* & \\
Command Staff & $4(5 \%)$ \\
Lieutenant & $4(5 \%)$ \\
Sergeant & $7(10 \%)$ \\
Patrol & $45(62 \%)$ \\
Detective & $10(14 \%)$ \\
Analyst & $3(4 \%)$ \\
Education & \\
Master's Degree & $48(66 \%)$ \\
Bachelor's Degree & $18(25 \%)$ \\
Associates Degree & $3(4 \%)$ \\
High School Degree & $4(5 \%)$ \\
Age & \\
53 or older & $16(22 \%)$ \\
$48-52$ & $15(21 \%)$ \\
$43-47$ & $8(11 \%)$ \\
$38-42$ & $15(21 \%)$ \\
$33-37$ & $8(11 \%)$ \\
$28-32$ & $5(7 \%)$ \\
$23-27$ & $5(7 \%)$ \\
Gender & \\
Male & $65(92 \%)$ \\
Female & $6(8 \%)$ \\
Race/Ethnicity & \\
White & $63(86 \%)$ \\
African American & $3(4 \%)$ \\
Asian & $3(4 \%)$ \\
Hispanic or Latino & $3(4 \%)$ \\
Native Hawaiian/Other Pacific Islander & $1(2 \%)$ \\
$*$ Average years on force was 17.84 with a standard deviation of & 10.20. \\
&
\end{tabular}




\section{Figure 1. Mobile Broadband Impact on Job Performance $(n=76)$}
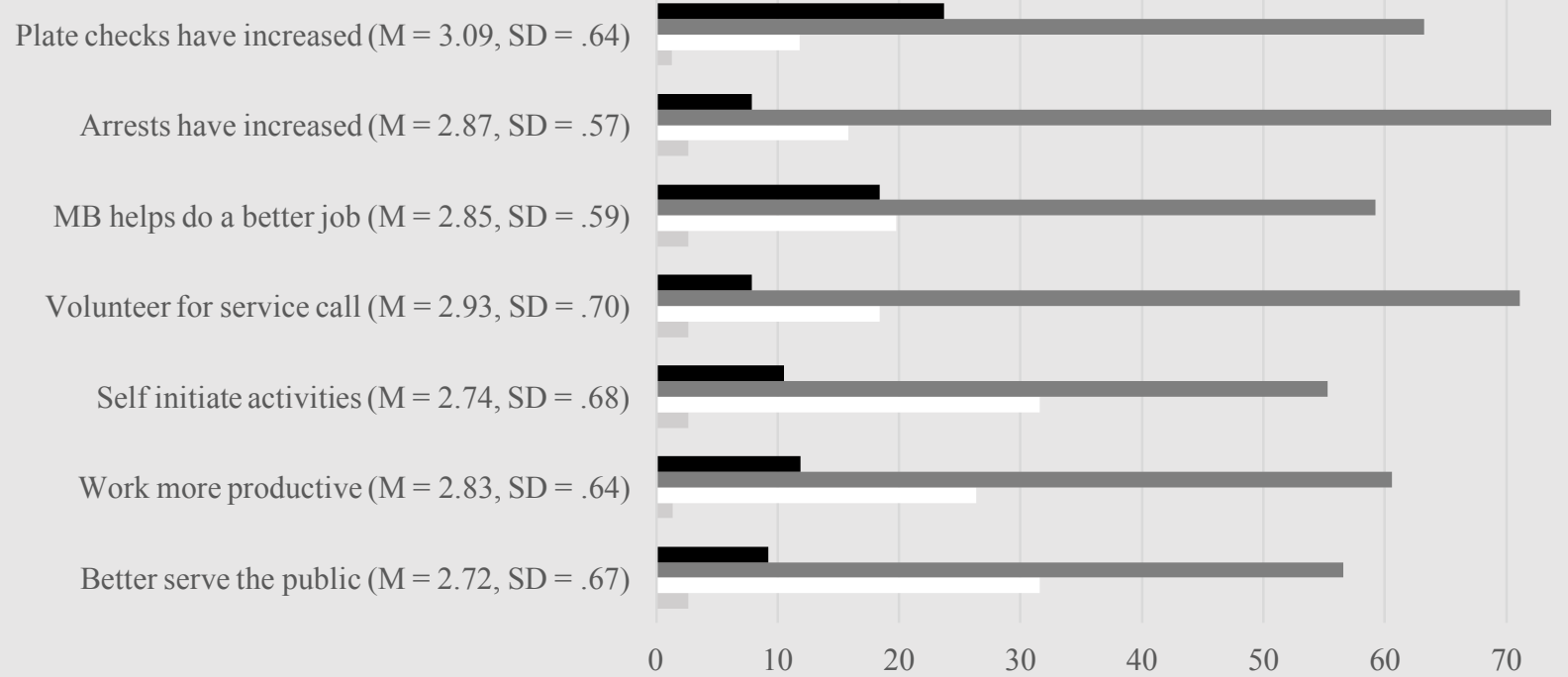

- Strongly Agree $\quad$ Agree Disgree Strongly Disagree

Note: Response sets range from "strongly disagree" (1) to "strongly agree" (4) with no neutral category. Higher scores indicate higher levels of agreement with the item. $\alpha=.905$.

Figure 2. Mobile Broadband vs. Cellular Data Communications $(n=76)$

Assigned to weak cell signal impacts job $(\mathrm{M}=2.80, \mathrm{SD}=.63)$

Cellular signal on patrol is a problem $(\mathrm{M}=2.96, \mathrm{SD}=.58)$

Prefer MB over cellular $(\mathrm{M}=2.75, \mathrm{SD}=.70)$

Access information easier $(\mathrm{M}=2.87, \mathrm{SD} .66)$

Speed of information processing is faster $(\mathrm{M}=3.16, \mathrm{SD}=.71)$

Amount of information is improved $(\mathrm{M}=3.28, \mathrm{SD}=.67)$

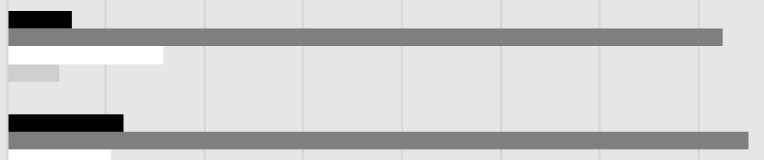

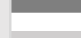

$$
+
$$

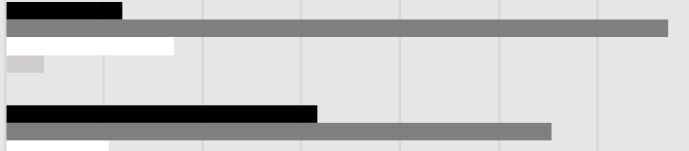

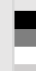

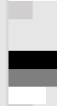

20

30

40

50

60

70

- Strongly Agree Agree Disgree Strongly Disagree

Note: Response sets range from "strongly disagree" (1) to "strongly agree" (4) with no neutral category. Higher scores indicate higher levels of agreement with the item. $\alpha=.771$. 
Figure 3. Respondent Perceptions of Time Impact from Mobile Broadband $(n=76)$
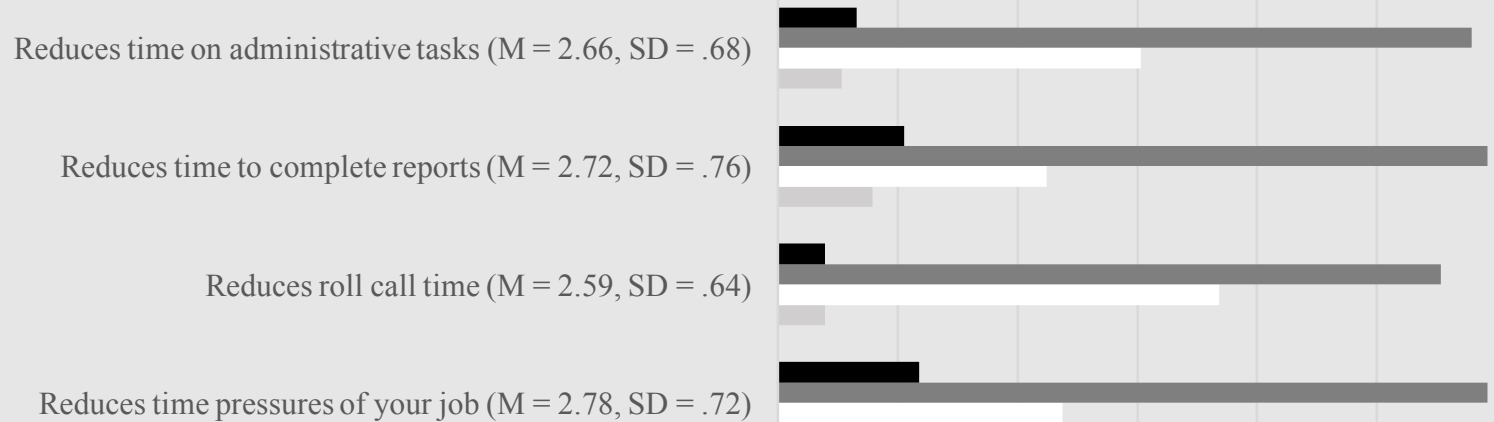

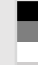

0

10

20

30

40

50

60

70

- Strongly Agree $\quad$ Agree Disgree Strongly Disagree

Note: Response sets range from "strongly disagree" (1) to "strongly agree" (4) with no neutral category. Higher scores indicate higher levels of agreement with the item. $\alpha=.868$.

Figure 4. Mobile Broadband Impact on Quality of Information ( $n=76)$

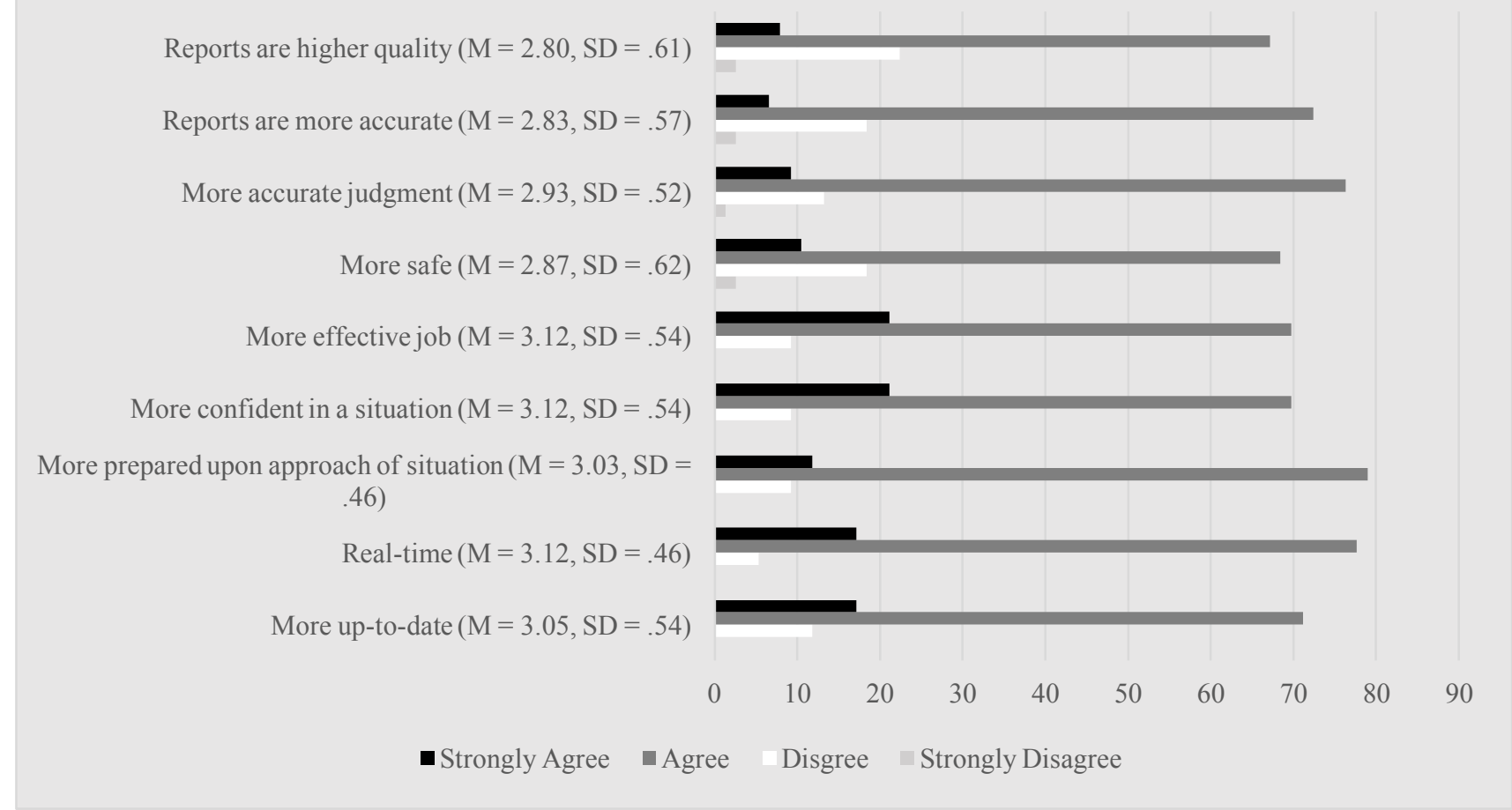

Note: Response sets range from "strongly disagree" (1) to "strongly agree" (4) with no neutral category. Higher scores indicate higher levels of agreement with the item. $\alpha=.938$. 
Figure 5. Adverse Effects of Mobile Broadband ( $n=76)$

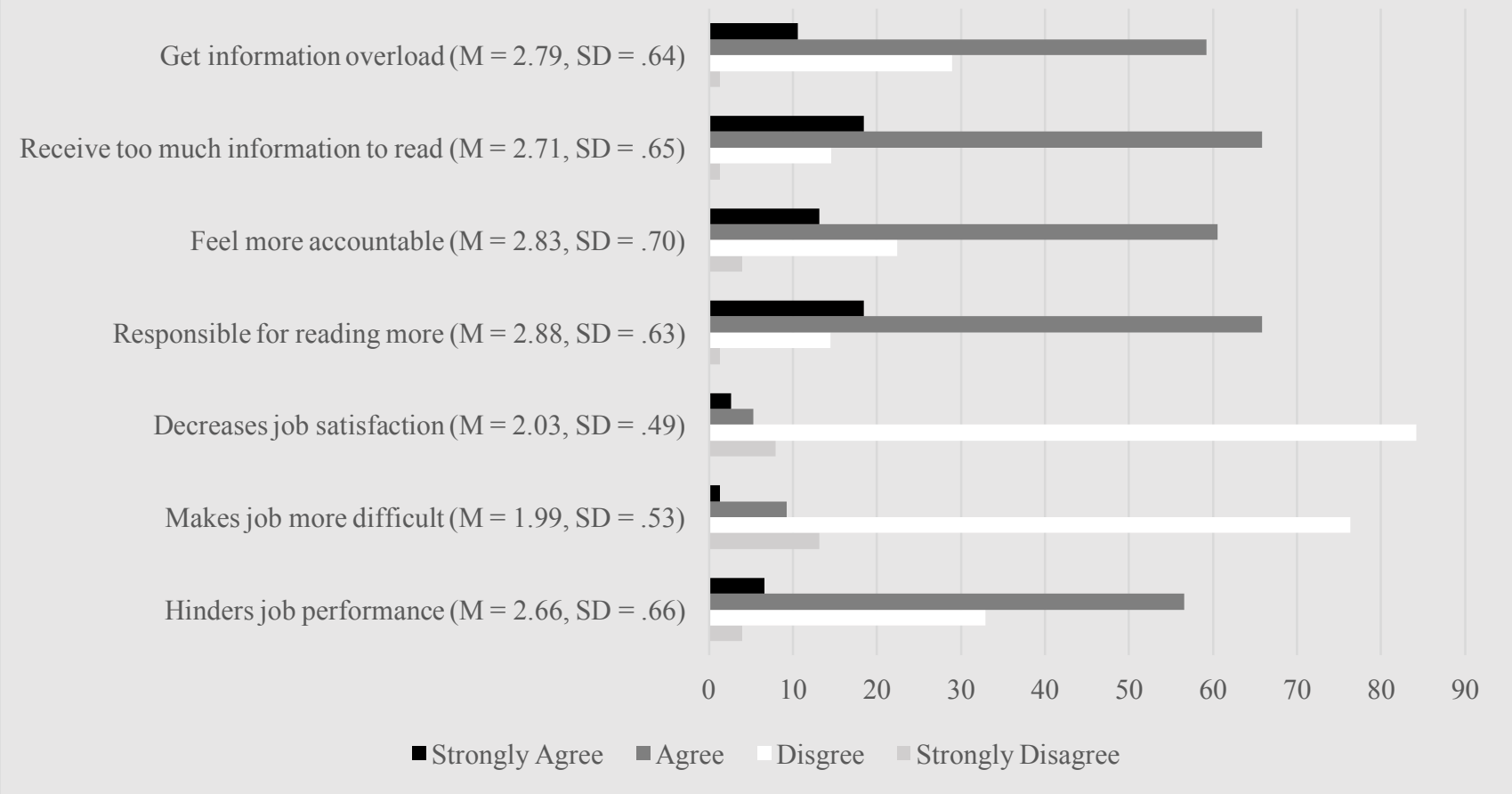

Note: Response sets range from "strongly disagree" (1) to "strongly agree" (4) with no neutral category. Higher scores indicate higher levels of agreement with the item. $\alpha=.694$. 